OPEN ACCESS

Edited by:

Özgür Bayram,

Maynooth University, Ireland

Reviewed by:

Eduardo Antonio Espeso,

Spanish National Research

Council (CSIC), Spain

Paul Daly,

Westerdijk Fungal Biodiversity Institute, Netherlands

*Correspondence:

Weixin Zhang

zhangwx@sdu.edu.cn

Weifeng Liu

weifliu@sdu.edu.cn

Specialty section:

This article was submitted to Microbial Physiology and Metabolism,

a section of the journal

Frontiers in Microbiology

Received: 18 May 2019

Accepted: 10 July 2019

Published: 06 August 2019

Citation:

Wang $L$, Yang $R$, Cao $Y$, Zheng $F$, Meng $X$, Zhong $Y$, Chen $G$, Zhang $W$ and Liu W (2019) CLP1, a Novel

Plant Homeo Domain

Protein, Participates

in Regulating Cellulase Gene

Expression in the Filamentous

Fungus Trichoderma reesei.

Front. Microbiol. 10:1700.

doi: 10.3389/fmicb.2019.01700

\section{CLP1, a Novel Plant Homeo Domain Protein, Participates in Regulating Cellulase Gene Expression in the Filamentous Fungus Trichoderma reesei}

\author{
Lei Wang, Renfei Yang, Yanli Cao, Fanglin Zheng, Xiangfeng Meng, Yaohua Zhong, \\ Guanjun Chen, Weixin Zhang* and Weifeng Liu*
}

State Key Laboratory of Microbial Technology, Microbial Technology Institute, Shandong University, Qingdao, China

The stringent regulatory network of cellulase gene expression in the filamentous fungus Trichoderma reesei involves multiple transcriptional regulators. However, identification and mechanistic investigation of these regulators are still insufficient. Here, we identified a novel transcriptional regulator, CLP1, a plant homeo domain (PHD) Protein that participates in regulating $T$. reesei cellulase gene expression. Phylogenetic analyses demonstrated that CLP1 homologs are widely distributed in filamentous fungi including Trichoderma, Penicillium, Fusarium, Neurospora, and Aspergillus species. We demonstrated that CLP1 is a nuclear protein and lack of CLP1 significantly impaired the induced expression of cellulase genes. ChIP experiments showed CLP1 binding to the cellulase gene promoters specifically under cellulose conditions and compromised XYR1 occupancy on the same promoters in the absence of CLP1 at the early induction stage. XYR1 overexpression fully rescued the defect in cellulase production but not the defect in conidia formation in the c/p1 null mutant. Further analysis showed that the PHD is required for the CLP1 appropriate subcellular localization as well as the induced cellulase gene expression and conidiation. Taken together, these data demonstrated an important role of CLP1 in the regulation of cellulase and xylanase gene expression in T. reesei.

Keywords: Trichoderma reesei, cellulase gene, transcriptional regulator, CLP1, XYR1

\section{INTRODUCTION}

Rapid and precise regulation of gene expression at the transcriptional level is essential for eukaryotic cells when confronted with environmental stresses and nutrition shift (Znameroski and Glass, 2013; Crawford and Pavitt, 2019). The filamentous fungus Trichoderma reesei is capable of efficiently initiating cellulase gene expression in response to insoluble cellulose and therefore has been applied for a long term for industrial cellulase production. T. reesei has also been established as an excellent model system for the investigation of mechanisms underlying induced gene expression (Druzhinina and Kubicek, 2017; Schmoll, 2018). Systematic characterization of the involved transcriptional factors would definitely contribute to understanding the whole regulatory network controlling cellulase gene expression in T. reesei.

Eukaryotic gene regulatory network involves multiple transcription factors and cofactors to integrate various environmental signals, and thus to exert regulatory effect on target genes by acting on their promoters (Tani et al., 2014). In T. reesei, several transcription factors involved in 
the regulation of cellulase gene expression have been identified, including the positive regulators XYR1 (Stricker et al., 2006), ACE3 (Häkkinen et al., 2014), CRZ1 (Chen et al., 2016), and ACE2 (Aro et al., 2001), and the negative regulators CRE1 (Strauss et al., 1995; Antoniêto et al., 2016), ACE1 (Saloheimo et al., 2000), and RCE1 (Cao et al., 2017). These identified factors belong to typical fungal transcription factors that bind to promoters via DNA-binding domains (Takashima et al., 1996; Saloheimo et al., 2000; Aro et al., 2001; Chen et al., 2016; Cao et al., 2017). Among others, XYR1 is the transcriptional activator crucial for cellulase and hemicellulose gene expression, although its precise acting mechanism is not yet clear (Stricker et al., 2006; Dos Santos Castro et al., 2016). Besides, chromatin status changes have been recently shown to occur in $T$. reesei for cellulase genes in context to the applied conditions (repressing/inducing) (Mellode-Sousa et al., 2015). Specific chromatin modifiers such as SAGA and LAE1 have also been identified to participate in modulating cellulase gene expression (Seiboth et al., 2012; Xin et al., 2013). Despite these advances, other yet-to-be known factors are speculated to be involved in this intricate and stringent regulatory network controlling cellulase gene expression. Systematic identification and characterization of these regulatory factors would undoubtedly contribute to unveiling the elaborate mechanism of cellulase gene regulation in $T$. reesei.

Eukaryotic DNA is wrapped in proteins called histones to form nucleosomes. Recruitment of nucleosome modifiers such as histone acetyltransferases to specific promoter regions facilitates the activation of a gene packaged within chromatin, by loosening the chromatin structure to uncover binding sites for regulators and for the transcriptional machinery (Mizzen and Allis, 1998; Church and Fleming, 2018). Proteins containing plant homeo domain (PHD) typified with a well-conserved $\mathrm{Zn}$ finger motif of the (Cys4)-His-(Cys3) type have been reported to be involved in chromatin-mediated transcription regulation (Aasland et al., 1995; Sanchez and Zhou, 2011; Bhushan et al., 2018). One such PHD finger-containing protein of Saccharomyces cerevisiae, CTI6, has been shown to participate in securing the rapid GAL1 transcriptional activation via acting in concert with the histone acetyltransferase-containing complex SAGA to alleviate Cyc8-Tup1-mediated repression (Papamichos-Chronakis et al., 2002; Han and Emr, 2011). On the other hand, CTI6 has been found to play important roles in regulating PHO5 gene in association with Rpd3-Sin3 histone deacetylase complex involved in transcriptional repression (Wang et al., 2011). Moreover, CTI6 is also required for the activation of several other genes including SUC2 involved in sucrose uptake (Papamichos-Chronakis et al., 2002), ICL1 and FBP1 involved in gluconeogenesis (Han and Emr, 2013), the hypoxic gene ANB1 (Papamichos-Chronakis et al., 2002), and STE6 involved in cell-type-specific expression (Vidal and Gaber, 1991; Puig et al., 2004). Despite this knowledge regarding S. cerevisiae CTI6, evidence about the function of other fungal CTI6-like proteins in regulating gene transcription is still lacking.

In this study, we searched the genome of $T$. reesei with yeast CTI6 as the query and retrieved a PHD finger-containing protein, CLP1. We found that CLP1 plays important roles in cellulase gene expression and conidia formation. The defect in cellulase expression but not conidia formation in the $c l p 1$ null mutant was fully rescued by XYR1 overexpression. We also showed that CLP1 is localized in the nucleus and recruited to cellulase gene promoters in the presence of cellulose. Furthermore, mutation analyses demonstrated that the integrity of the PHD is essential for the appropriate nuclear localization and function of CLP1.

\section{MATERIALS AND METHODS}

\section{Strains, Media, and Culture Conditions}

T. reesei TU-6 (ATCC MYA-256), a uridine auxotroph of T. reesei, was used throughout this work as the parental strain. A pyr4complemented TU-6 strain named TU6-RP (Cao et al., 2017), wherein the pyr4 gene was homologously integrated into its native locus, was used as the control strain. For analyses of (hemi) cellulase production, T. reesei cells were pre-cultured at $30^{\circ} \mathrm{C}$ for $48 \mathrm{~h}$ on a rotary shaker $(200 \mathrm{rpm})$ in 1-L Erlenmeyer flasks containing $250 \mathrm{ml}$ of Mandels-Andreotti (MA) medium supplemented with $1 \%(\mathrm{v} / \mathrm{v})$ glycerol. The mycelia were then harvested by filtration and washed twice with medium containing no carbon source. Equal amounts of mycelia were transferred to fresh MA medium containing $10 \mathrm{~g} / \mathrm{L}(\mathrm{w} / \mathrm{v})$ Avicel or $5 \mathrm{~g} / \mathrm{L}(\mathrm{w} / \mathrm{v})$ xylan as the sole carbon source, and the incubation was continued for the indicated time periods (Wang et al., 2018). Uridine at a final concentration of $10 \mathrm{mM}$ was added for $T$. reesei cultivation when necessary. $T$. reesei was grown in daylight and dark cycles for both plate and liquid culture. Escherichia coli DH5a (TSINGKE, Beijing, China) was used for routine plasmid construction.

\section{Plasmids and Recombinant T. reesei Strains Construction}

To delete the $c l p 1$ gene, two approximately $2.0 \mathrm{~kb}$ of $c l p 1 \mathrm{up}$ and downstream noncoding sequences were amplified from T. reesei genomic DNA and ligated into pDonor-pyr4 (Zhang et al., 2013) via BP cloning to yield the deletion vector pDonorpyr4-clp1, which was used to transform $T$. reesei TU-6 after linearization with I-SceI to result in the $\Delta c l p 1$ strain. To construct the plasmid $\mathrm{P}_{g p d}-c l p 1-\mathrm{T}_{t r p C}$, the full-length $c l p 1$ was amplified from the genomic DNA of T. reesei and inserted into the $\mathrm{P}_{g p d}-\mathrm{T}_{t r p C^{-}}$ $h p h$ vector, which was generated by inserting the gpd promoter and $\mathrm{T}_{\text {trpC }}$ terminator amplified from the genomic DNA of $A$. nidulans into the pUC19-hph plasmid (Zhou et al., 2012). The PHD mutant of clp1 with two mutations of C145A and H150A and the UIM (ubiquitin interacting motif) deletion mutant of clp1 were obtained by overlap-extension PCR (Heckman and Pease, 2007; Zhang et al., 2015), and similarly inserted into the $\mathrm{P}_{g p d^{-}}-\mathrm{T}_{t r p C}-h p h$ plasmid to construct $\mathrm{P}_{g p d}-c l p 1 \_$PHDM-T $\mathrm{T}_{t r p C}$ and $\mathrm{P}_{g p d^{-}}-c l p 1 \_\Delta \mathrm{UIM}-\mathrm{T}_{t r p C}$, respectively. These three plasmids $\mathrm{P}_{g p d}-c l p 1-$ $\mathrm{T}_{t r p C}, \mathrm{P}_{g p d}-c l p 1 \_\mathrm{PHDM}-\mathrm{T}_{t r p C}$, and $\mathrm{P}_{g p d}-c l p 1 \_\Delta \mathrm{UIM}-\mathrm{T}_{t r p C}$ were transformed to the $\Delta c l p 1$ strain to obtain the Reclp1, Reclp1_PHDM, and Reclp1_AUIM strains, respectively. To express the mCherrytagged histone $\mathrm{H} 2 \mathrm{~B}$, a reference nuclear protein, in $T$. reesei, the xyr1 sequence of the $\mathrm{P}_{\text {tcul }}-m$ Cherry-xyr1 (Zheng et al., 2017) vector was replaced by the $\mathrm{H} 2 \mathrm{~B}$ coding sequence to generate 
$\mathrm{P}_{\text {tcul }}-m C h e r r y-h 2 b$, which was then transformed into TU-6, resulting in the $m C h e r r y-h 2 b$ strain. To determine the subcellular localization of the native CLP1, the coding sequence of CLP1 fused with a C-terminal GFP was inserted into $\mathrm{pMDP}_{\text {tcul }}-\mathrm{T}_{\text {trpC }}$ (Lv et al., 2015) to result in $\mathrm{P}_{t c u l}-c l p 1-g f p-\mathrm{T}_{t r p C}$, which was subsequently co-transformed with pRLMex-30 (Mach et al., 1994) into mCherry$h 2 b$ to generate the mCherry-h2b\&clp1-gfp strain. The same strategy was used for construction of $m$ Cherry-h2b\&clp1_PHDM$g f p$ and $m$ Cherry-h2b\&clp1_AUIM-gfp strains, which are used for the determination of the localization of the two CLP1 mutants, respectively. To detect the recruitment of CLP1 on the cellulase gene promoters, the $\mathrm{P}_{\text {tul }}-c l p 1-g f p-\mathrm{T}_{\text {trpc }}$ plasmid was co-transformed with pRLMex-30 into $\Delta c l p 1$, to result in the $\mathrm{P}_{\text {tcul }}-c l p 1-g f p$ strain. To overexpress ACE3 in the $\Delta c l p 1$ strain, the ace 3 coding sequence was amplified from cDNA and inserted into $\mathrm{pMDP}_{\text {tcul }}-\mathrm{T}_{\text {trpC }}$ (Lv et al., 2015) to generate $\mathrm{pMDP}_{t c u 1}-$ ace3- $\mathrm{T}_{\text {trpc. }}$. Then, $\mathrm{pMDP}_{t c u 1^{-}}$ ace3- $T_{t r p C}$ was co-transformed with pRLMex-30 into $\Delta c l p 1$ to result in the $\triangle c l p 1 \& O E a c e 3$ strain. Similarly, the $\mathrm{pMDP}_{t c u 1}$-xyr1$\mathrm{T}_{\text {trpC }}$ (Lv et al., 2015) was co-transformed with pRLMex-30 into $\Delta c l p 1$ to result in the $\Delta c l p 1 \& \mathrm{OExyr} 1$ strain. All the fungal transformations were performed as described by Penttilä et al. (1987). All the strains used are listed in Table 1 and verification of correct DNA integration in the mutant strains is shown in Supplementary Figure S1.

\section{Vegetative Growth and Conidiation Analyses}

To analyze T. reesei vegetative growth, equal amounts of mycelia were inoculated on minimal media agar plates containing $1 \%$ $(w / v)$ glucose, cellobiose, xylose, and arabinose incubated at $30^{\circ} \mathrm{C}$ for 2 days. To analyze T. reesei biomass on liquid MA medium with $1 \%$ glucose, equal amounts of mycelia were inoculated and the mycelia collected at growth intervals were dried and then weighed. For conidiation analysis, mycelia were inoculated on malt extract agar plates and incubated at $30^{\circ} \mathrm{C}$ for 5 days. The number of conidia was counted with a hemocytometer on an inverted optical microscope (Olympus, Tokyo, Japan).

\section{Quantitative RT-PCR}

Total RNA was extracted using TRIzol reagent (Sangon, Shanghai, China) and purified using the TURBO DNA-free kit (Ambion, Austin, TX, USA) to remove gDNA according to the manufacturer's instructions. Reverse transcription was carried out using the PrimeScript RT reagent Kit (Takara, Tokyo, Japan) according to the instructions. Quantitative PCR was performed on LightCycler 480 II (Roche, Basel, Switzerland). Amplification reactions were performed using the SYBR Green Supermix (Takara, Tokyo, Japan) according to the manufacturer's instructions. Data analysis was performed using the comparative CT method (Schmittgen and Livak, 2008). The endogenous actin gene was used as the control for normalization.

\section{Enzymatic Activity and Protein Analysis}

Extracellular cellulase activities were analyzed by measuring the amount of released $p$-nitrophenol using $p$-nitrophenyl-Dcellobioside ( $p$ NPC; Sigma) as substrate. The assays were
TABLE 1 | Strains used in this study.

\begin{tabular}{|c|c|c|}
\hline Strains & Description & Source \\
\hline TU-6 & ATCC MYA-256 & Laboratory stock \\
\hline TU6-RP & $\begin{array}{l}\text { TU-6 complemented with pyr } 4 \\
\text { expression cassette }\end{array}$ & (Cao et al., 2017) \\
\hline$\Delta c / p 1$ & Deletion of clp1 in TU-6 & This study \\
\hline Reclp1 & $\begin{array}{l}\text { Expression of CLP1 under a } \\
\text { constitutive promoter in } \Delta c / p 1\end{array}$ & This study \\
\hline Reclp1_PHDM & $\begin{array}{l}\text { Expression of CLP1 with two point } \\
\text { mutations in PHD (C145A and } \\
\text { H150A) in } \triangle \text { clp1 }\end{array}$ & This study \\
\hline Reclp1_.UUIM & $\begin{array}{l}\text { Expression of CLP1 without } \\
\text { UIM in } \Delta c / p 1\end{array}$ & This study \\
\hline$\triangle c / p 1 \& O E x y r 1$ & Overexpression of XYR1 in $\Delta c / p 1$ & This study \\
\hline$\triangle c / p 1 \&$ OЕасе3 & Overexpression of ACE3 in $\triangle c / p 1$ & This study \\
\hline$P_{\text {tou1 }}-c / p 1-g f p$ & $\begin{array}{l}\text { Expression of CLP1 tagged with } \\
\text { C-terminal GFP in } \Delta c / p 1\end{array}$ & This study \\
\hline mcherry-h2b & $\begin{array}{l}\text { Expression of histone } \mathrm{H} 2 \mathrm{~B} \text { tagged } \\
\text { with } \mathrm{N} \text {-terminal mCherry in TU-6 }\end{array}$ & This study \\
\hline mcherry-h2b\&c/p1-gfp & $\begin{array}{l}\text { Co-expression of CLP1-GFP and } \\
\text { mCherry-H2B in TU-6 }\end{array}$ & This study \\
\hline $\begin{array}{l}\text { mcherry-h2b\& } \\
\text { clp1_PHDM-gfp }\end{array}$ & $\begin{array}{l}\text { Co-expression of CLP1 PHD } \\
\text { mutant tagged with GFP (CLP1_ } \\
\text { PHDM-GFP) and mCherry-H2B in } \\
\text { TU-6 }\end{array}$ & This study \\
\hline $\begin{array}{l}\text { mcherry-h2b\& } \\
\text { clp1__UIM-gfp }\end{array}$ & $\begin{array}{l}\text { Co-expression of GFP-tagged CLP1 } \\
\text { without the UIM (CLP1__UIM-GFP) } \\
\text { and mCherry-H2B in TU-6 }\end{array}$ & This study \\
\hline
\end{tabular}

performed in $200 \mu \mathrm{l}$ of reaction mixtures containing $50 \mu \mathrm{l}$ of diluted culture supernatant and $50 \mu \mathrm{l}$ of substrate plus $100 \mu \mathrm{l}$ of $50 \mathrm{mM}$ sodium acetate buffer $(\mathrm{pH} 4.8)$ and were then incubated at $45^{\circ} \mathrm{C}$ for $30 \mathrm{~min}$. One unit $(\mathrm{U})$ of $p$ NPCase activity is defined as the amount of enzyme releasing $1 \mu \mathrm{mol}$ of $p N P$ per minute. Xylanase activities were determined by measuring the amount of released xylose using xylan as substrate. Briefly, a reaction mixture containing $60 \mu \mathrm{l}$ of diluted culture supernatant and $60 \mu \mathrm{l}$ of beechwood xylan $(5 \mathrm{~g} / \mathrm{L})$ dissolved in $50 \mathrm{mM}$ sodium acetate buffer ( $\mathrm{pH} 4.8$ ) was incubated at $50^{\circ} \mathrm{C}$ for $15 \mathrm{~min}$. The reducing sugar released in the mixture was determined using DNS method with xylose as the standard. One unit of enzyme activity was defined as the amount of enzyme capable of releasing $1 \mu \mathrm{mol}$ of xylose per minute. SDS-PAGE was performed according to standard protocols as described by Laemmli (1970) with a 5\% stacking gel and a $10 \%$ separating gel running at $160 \mathrm{~V}$ for $1.5 \mathrm{~h}$. Equal amounts of culture supernatant relative to biomass were loaded for SDS-PAGE analysis of the extracellular proteins.

\section{Chromatin Immunoprecipitation}

Chromatin immunoprecipitation (ChIP) assays were performed as described previously (Cao et al., 2017; Zheng et al., 2017). Briefly, the mycelia were incubated in MA medium containing $1 \%(\mathrm{w} / \mathrm{v})$ glucose or Avicel plus $1 \%$ formaldehyde at $30^{\circ} \mathrm{C}$ for 10 min with shaking before the cross-linking was quenched via adding $25 \mathrm{ml}$ of $1.25 \mathrm{M}$ glycine. The mycelia were then collected; suspended in $50 \mathrm{mM}$ HEPES lysis buffer at $\mathrm{pH} 7.5$ plus $150 \mathrm{mM}$ $\mathrm{NaCl}, 1 \mathrm{mM}$ EDTA, 0.5\% (v/v) Triton X-100, 0.1\% (w/v) sodium deoxycholate, $0.1 \%$ (w/v) SDS, $1 \mathrm{mM}$ PMSF (phenylmethanesulfonyl fluoride), $1 \mu \mathrm{g} / \mathrm{ml}$ leupeptin, and $1 \mu \mathrm{g} / \mathrm{ml}$ pepstatin; and broken 
with glass beads $(0.45 \mathrm{~mm})$. Chromatin DNA was further sonicated to obtain sheared DNA fragments with an average size of approximately $500 \mathrm{bp}$. Immunoprecipitation with the antibodies against XYR1 and GFP, respectively, was performed as previously described (Cao et al., 2017; Wang et al., 2019). Quantitative PCR was performed on the precipitated chromatin DNAs using the same procedure with qRT-PCR. Relative enrichment of the DNAs was calculated as a percentage of the input DNA.

\section{Subcellular Localization of CLP1 and Its Mutants}

For visualization of the histone H2B, CLP1, and CLP1 mutants, spores of $m$ Cherry-h2b, mCherry-h2b\&clp1-gfp,

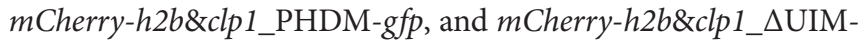
$g f p$ recombinant strains were inoculated into minimal medium containing $1 \%(\mathrm{w} / \mathrm{v})$ glucose or Avicel, respectively. Mycelia after cultivation of $24 \mathrm{~h}$ (glucose) or $48 \mathrm{~h}$ (Avicel) were harvested for microscopic observation. Fluorescence was detected with a Nikon Eclipse 80i fluorescence microscope. The captured pictures of GFP and mCherry were merged using ImageJ2x software.

\section{Sequence Analysis}

Amino acid sequences from $T$. reesei and other relevant species were obtained from the Uniprot ${ }^{1}$ databases. The phylogenetic tree was constructed by the maximum likelihood method using protein sequences aligned by the Muscle method based on the JTT model with MEGA6 (Hall, 2013; Tamura et al., 2013). Positions containing alignment gaps and missing data were partially deleted. Statistical confidence of the inferred phylogenetic relationships was assessed by performing 1,000 bootstrap replicates.

\section{Statistical Analysis}

Statistical analysis was performed using the Student's $t$ test analysis. At least two to three biological replicates were performed for each analysis, and the results and errors are the mean and $\mathrm{SD}$, respectively, of these replicates.

\section{RESULTS}

\section{Identification of the clp1 Gene That Encodes a CTI6-Like Protein in T. reesei}

S. cerevisiae PHD protein CTI6 has been implicated as an important factor in regulating the expression of several genes including SUC2, GAL1, ANB1, ICL1, and FBP1 (PapamichosChronakis et al., 2002; Han and Emr, 2013). To analyze whether CTI6 homologous protein is present in the filamentous fungus T. reese $i$, we searched the $T$. reesei genome with CTI6 as a query and retrieved one gene (Trire2_27020 or TrireRUTC30_1_86967,

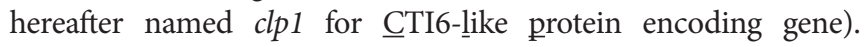
Although the overall amino acid sequence similarity and identity of CLP1 with that of CTI6 are only 29 and 19\%, respectively, a well-conserved PHD finger of the $\left(\mathrm{Cys}_{4}\right)$-His- $\left(\mathrm{Cys}_{3}\right)$ type was readily detected in CLP1 (residues 104-181) (Aasland et al.,

${ }^{1}$ https://www.uniprot.org/
1995; Bienz, 2006; Sanchez and Zhou, 2011). Moreover, an additional conserved UIM was found in CLP1 (residues 244-263)

(Figure 1A; Hofmann and Falquet, 2001). The UIM (or LALAL motif) is a stretch of about 20 amino acid residues that is present in a variety of proteins either involved in ubiquitination and ubiquitin metabolism or known to interact with ubiquitinlike modifiers (Buchberger, 2002; Oldham et al., 2002; Polo et al., 2002). Unlike the PHD finger, the UIM present in CLP1 is not present in yeast CTI6 (Figure 1A).

To analyze the evolutionary relationship between CLP1 homologs from filamentous fungi and Saccharomycotina/ Saccharomyces CTI6, phylogenetic analysis of CLP1 and its orthologs in other filamentous fungi including Trichoderma, Penicillium, Fusarium, Neurospora, and Aspergillus species as well as CTI6 orthologs from Saccharomycotina/Saccharomyces species was performed (Figure 1B). The results revealed that CTI6 homologs from Saccharomycotina/Saccharomyces species form a distinct cluster from those CLP1 homologs of filamentous fungi. Nevertheless, CLP1 is highly conserved in Trichoderma species with an overall sequence identity between 85 and 98\%. Relatively higher sequence identity also exists among orthologs from Fusarium ( 58\%) and Neurospora ( 43\%), whereas lower sequence identity is found with those from the distantly related Penicillium (30-35\%) and Aspergillus (30-34\%) species, indicating that CLP1 orthologs are widely distributed in the above filamentous fungi although none of these orthologs have been characterized. Notably, the conserved PHD is present in all the above CLP1 orthologs (Figure 1C) whereas the UIM is observed in a vast majority of them except those in Neurospora species (Figure 1D).

\section{T. reesei clp1 Mutant Exhibits a Conidiation Defect}

To figure out the physiological role of $c l p 1$ in $T$. reesei, the $c l p 1$ null mutant was generated by specifically deleting its coding sequence, and its phenotypes in growth and conidiation were investigated. As shown in Figures 2A,B, the hyphal growth of the $c l p 1$ null mutant on agar plates with different carbon sources was all slightly compromised after incubation at $30^{\circ} \mathrm{C}$ for 2 days. However, the growth rate of the mutant strain is comparable to that of the control strain when cultured in liquid MA medium in the presence of glucose with roughly equivalent final biomass (Figure 2C). In contrast with the hyphal growth, the $\Delta c l p 1$ mutant exhibited a severe defect in sporulation on malt extract agar plate (Figure 2A), as demonstrated by the dramatic decrease in conidia formation as compared with the control strain (Figure 2D). The defect of the mutant strain in both growth and conidiation was rescued by reintroduction of a clp 1 expression cassette under the control of the A. nidulans gpd promoter (Figures 2A,D). Taken together, these results demonstrate that CLP1 plays an important physiological role in T. reesei, especially in asexual conidia formation.

\section{Deletion of clp1 Compromised T. reesei Cellulase Production}

To see the effect of the absence of CLP1 on cellulase production, the $\Delta c l p 1$ and the control strains were simultaneously inoculated on solid medium covered with a layer of $0.4 \%(\mathrm{w} / \mathrm{v})$ ground 


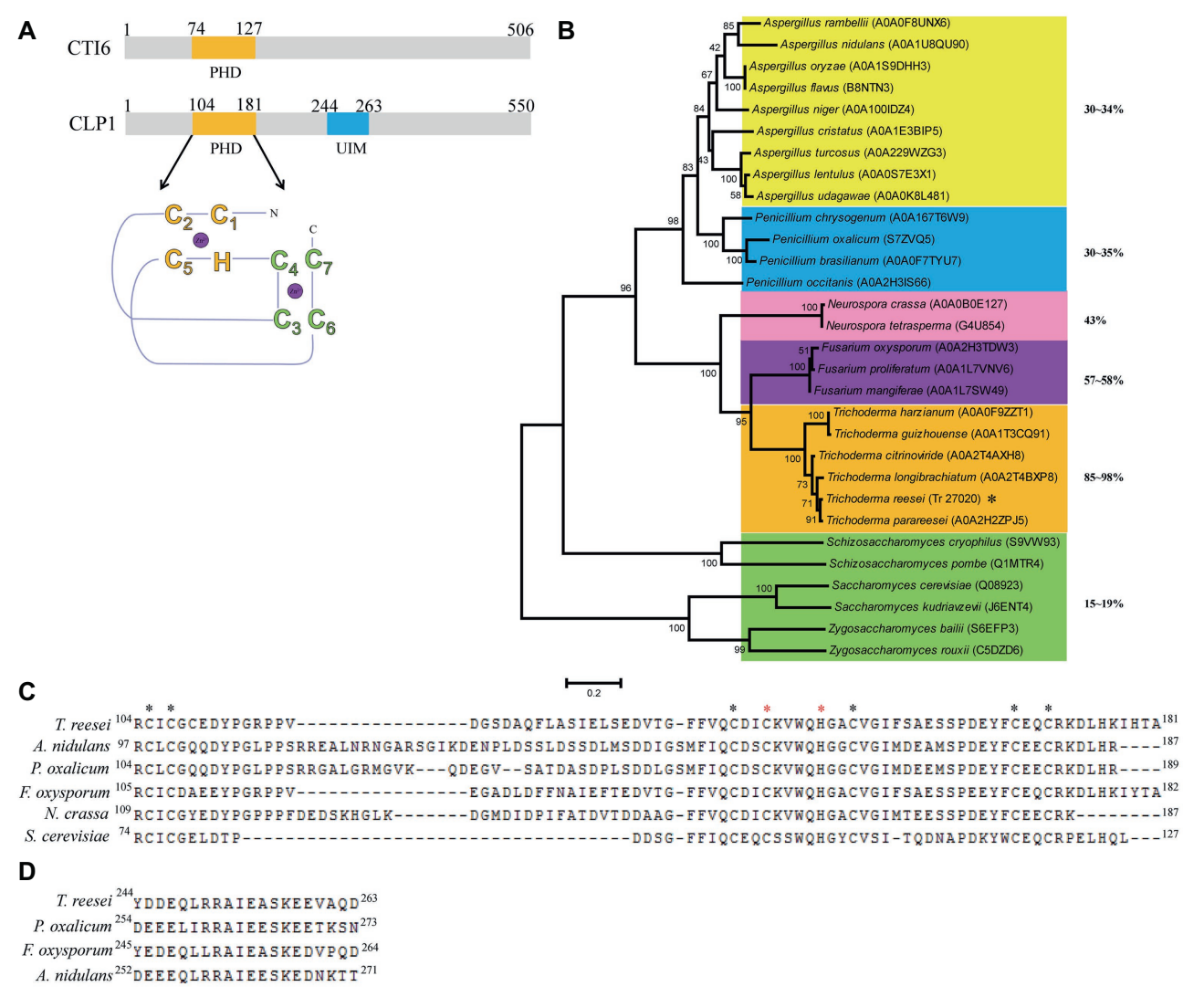

FIGURE 1 | Sequence and phylogenetic analysis of CLP1 and its homologs. (A) Schematic diagram of CLP1 containing a conserved C4HC3 PHD finger and a UIM. The yeast CTI6 diagram is also shown. (B) Phylogenetic analysis of CLP1 and its homologs from Trichoderma, Penicillium, Fusarium, Neurospora, and Aspergillus species. The phylogenetic tree was generated with MEGA6. Numbers on the tree branches represent the bootstrap support calculated per 1,000 bootstrap replicates. The sequence identity between CLP1 and its homologs is indicated. (C) Sequence alignment of the PHD in CLP1 and its homologs. The conserved amino acid of $\mathrm{C}_{4} \mathrm{HC}_{3}$ motif is indicated by asterisks and the two residues ( $\mathrm{C} 145$ and $\left.\mathrm{H} 150\right)$ to be mutagenized in this study are indicated with red asterisks. (D) Sequence alignment of the UIMs in CLP1 and its homologs.

Avicel. After incubation at $30^{\circ} \mathrm{C}$ for 5 days, $\Delta c l p 1$ colonies exhibited a much smaller hydrolytic zone than the control cells (Figure 3A), suggesting that $c l p 1$ deletion impaired cellulase synthesis. To verify this result, the mutant and control strains were cultured in MA liquid medium with $1 \%(\mathrm{w} / \mathrm{v})$ Avicel as the sole carbon source, and the extracellular cellulase activities were determined. As shown in Figure 3B, the $\Delta c l p 1$ strain exhibited a significant defect in extracellular $p$ NPC hydrolytic activities compared to the control strain, which was largely rescued in the Reclp1 strain (Figure 3B). SDS-PAGE analysis of the extracellular secreted proteins also showed a dramatic reduction in intensity for all corresponding bands in the mutant compared to those displayed by control strain (Figure 3C). The clp1 deletion also caused a drastic reduction in the extracellular xylanase activity in the $\Delta c l p 1$ mutant compared to the control strain, which was largely rescued in the Reclp1 strain when cultivated with xylan (Figure 3D). Further quantitative RT-PCR analyses indicated that the relative transcriptional expression of the two main cellulase genes $c e l 7 a$ and $c e l 7 b$ was dramatically decreased in $\Delta c l p 1$ (Figures 3E,F), demonstrating that the defective cellulase production resulting from $c l p 1$ deletion occurred at the transcriptional level. To see the effect of the absence of CLP1 on other cellulase regulators, their endogenous transcripts were also determined (Figures 3G-I). The results showed that, whereas the transcription of ace 3 was significantly decreased on Avicel induction, the expression of $x y r 1$ was affected only at an early point of induction but remained comparable to the control strain later after. The expression of cre 1 was hardly affected in the absence of CLP1 compared with that of the control strain. Together, the data indicate that CLP1 plays an important role in regulating (hemi)cellulase production.

\section{The CLP1 Plant Homeo Domain Is Essential for T. reesei Cellulase Production and Conidiation}

To ascertain whether the PHD finger or the UIM in the CLP1 protein is important for the above-observed phenotypes, sitedirected mutagenesis toward the PHD to disrupt its integrity or deletion of the UIM was performed. The cysteine residue 145 and histidine residue 150 that were predicted to be zinc ligands (Puig et al., 2004; Sanchez and Zhou, 2011) were simultaneously replaced by alanine to construct the CLP1_PDHM mutant while the UIM was deleted to generate the CLP1_AUIM 

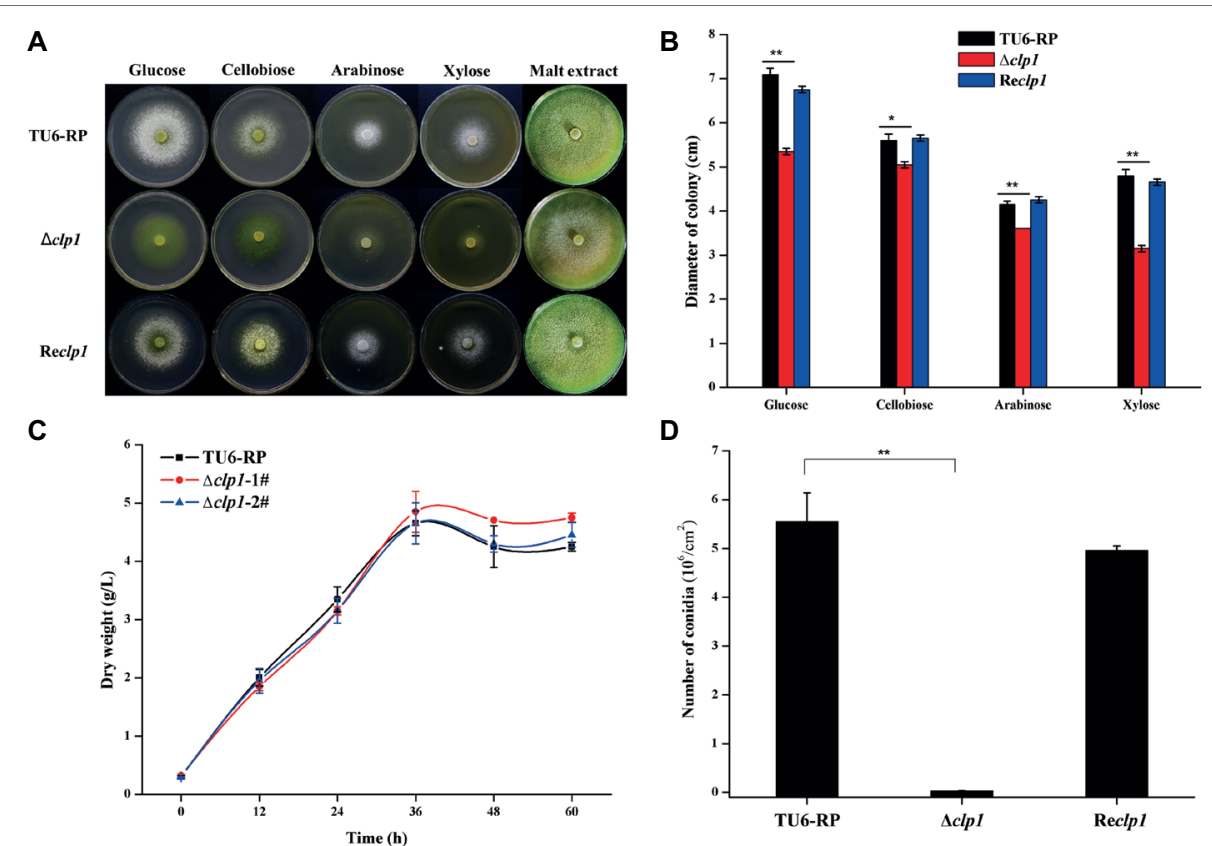

FIGURE 2 | The effect of the absence of CLP1 on the vegetative growth and conidiation of T. reesei. (A) Colony growth of the $\triangle$ clp1, Reclp1, and TU6-RP strains on different carbon sources and conidia formation on malt extract. (B) Quantitative determination of the colony diameters as shown in (A). (C) Biomass accumulation of the TU6-RP and two independent transformants of $\Delta c / p 1$ cultured with $1 \%$ (w/v) glucose as the sole carbon source. (D) Counting of conidia formed by $\Delta c / p 1$, Reclp1, and TU6-RP strains with a hemocytometer after cultivation on malt extract agar for 5 days. Significant difference $\left(t\right.$ test, ${ }^{\star} p<0.05$, $\left.{ }^{\star \star} p<0.01\right)$ was observed in colony diameter and conidia formation between the TU6-RP and the $\triangle c / p 1$ strains. Values represent the mean of two to three biological replicates. Error bars are the SD from these replicates.

mutant. These CLP1 mutants were individually expressed under the control of the $g p d$ promoter in $\Delta c l p 1$ to generate the Reclp1_PDHM and Reclp1_AUIM strains, respectively. While UIM deletion hardly affected the extracellular cellulase activity and conidiation, the double point mutation of the PHD was unable to complement the $\Delta c l p 1$ conidiation and cellulase production defects (Figures 4A-C). These results strongly suggest that the integrity of the CLP1 PHD finger is important for its function in cellulase synthesis and asexual conidia formation.

\section{CLP1 Is a Nuclear Protein and Recruited to the Cellulase Gene Promoter Upon Cellulose Induction}

Given that the absence of CLP1 markedly impaired the transcription of cellulase genes, and that yeast CTI6 acts as a nuclear protein to mediate recruitment of specific regulators to the targeted promoters, we determined the subcellular localization of CLP1 in $T$. reesei. CLP1 epitope-tagged at the C-terminus with green fluorescent protein (GFP) was expressed in T. reesei TU-6 cells simultaneously expressing histone H2B that was epitope-tagged with the mCherry at the N-terminus. Fluorescence microscopic analysis showed that the green fluorescent signals from CLP1-GFP merged well with the red fluorescent signals from the mCherry-H2B, regardless whether the recombinant $T$. reesei cells were cultivated under the non-inducing (glucose) or the inducing (cellulose) condition (Figure 5A), demonstrating that CLP1 is a nuclear protein.
Mutagenesis of amino acid residues 145 and 150 (C145 and H150 mutant CLP1_PDHM) or removal of the UIM (mutant CLP1_AUIM) did not affect CLP1-GFP nuclear localization. However, unlike CLP1_AUIM, CLP1_PDHM-GFP displayed an irregular pattern of accumulation in the nucleus (Figure 5B), suggesting that the integrity of the PHD finger contributes to the appropriate subcellular localization and function of CLP1 in the processes of cellulase production and conidiation.

To gain further insight into whether CLP1 is directly involved in the transcriptional regulation of cellulase genes, we expressed GFP-tagged CLP1 in $\Delta c l p 1$, which was then subject to chromatin immunoprecipitation (ChIP) assays to determine CLP1 occupancy on cellulase gene promoters. As shown in Figure 5C, a significant enrichment of CLP1 was observed in the promoter regions of two main cellulase encoding genes, cel7a and $c e l 7 b$, compared with the control cells that were both cultured under Avicel conditions. However, no such enrichment was observed under glucose conditions (Figure 5C), suggesting that CLP1 is recruited to the cellulase gene promoters specifically upon cellulose induction to be involved in cellulase gene activation.

\section{Overexpression of XYR1 Fully Rescued the Defect in Cellulase Production but Not Conidiation Resulting From clp1 Deletion}

As described above, clp1 mutants are defective for the induced transcription of ace 3 while $x y r 1$ transcription was also decreased at an early stage of induction. Both genes have been reported 


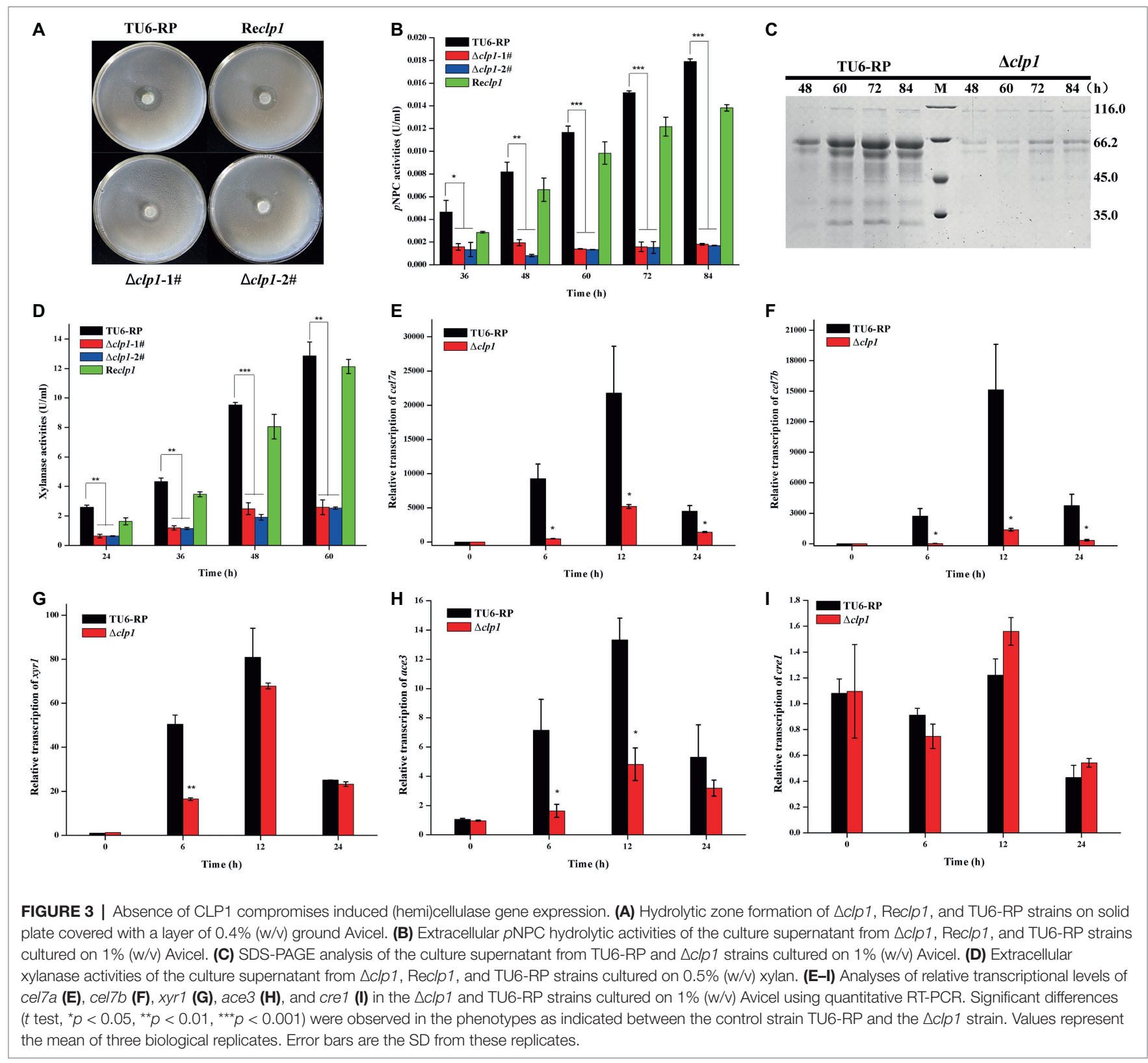

to encode key transactivators in regulating $T$. reesei cellulase gene expression (Stricker et al., 2006; Ma et al., 2016). We determined XYR1 occupancy on cellulase gene promoters in both TU6-RP and $\Delta c l p 1$ cells using ChIP analyses (Figures 6A,B). In contrast with control cells wherein a marked increase in XYR1 binding to cellulase gene promoters was observed when the carbon source was shifted from glycerol to Avicel, XYR1 binding was compromised in $\Delta c l p 1$ cells only during the early cultivation on Avicel, which is consistent with the pattern of xyr1 transcription. We next overexpressed ACE3 or XYR1 using the tcu1 promoter in $\Delta c l p 1$, to investigate whether sufficient amounts of ACE3 or XYR1 would rescue the defect in (hemi)cellulase production in the clp1 mutant. While ACE3 overexpression had no effect on the defective cellulase gene expression (Supplementary Figure S2), XYR1 overexpression fully restored the induced cellulase and xylanase production in $\Delta c l p 1$ (Figures 6C,D). XYR1 overexpression, however, had hardly any effect on the compromised conidia formation in $\Delta c l p 1$ (Figures $6 \mathrm{E}, \mathbf{F}$ ). These results suggest that CLP1 participates in modulating cellulase gene expression not only by facilitating either xyr1 expression or XYR1 binding to cellulase gene promoters, but also may contribute to the transcriptional activation process mediated by XYR1.

\section{DISCUSSION}

T. reesei is one of the most important cellulase-producing fungi applied in industry. To identify more regulators involved in T. reesei cellulase gene expression, we performed a blast analysis in its genome with the sequence of CTI6, which is a novel 

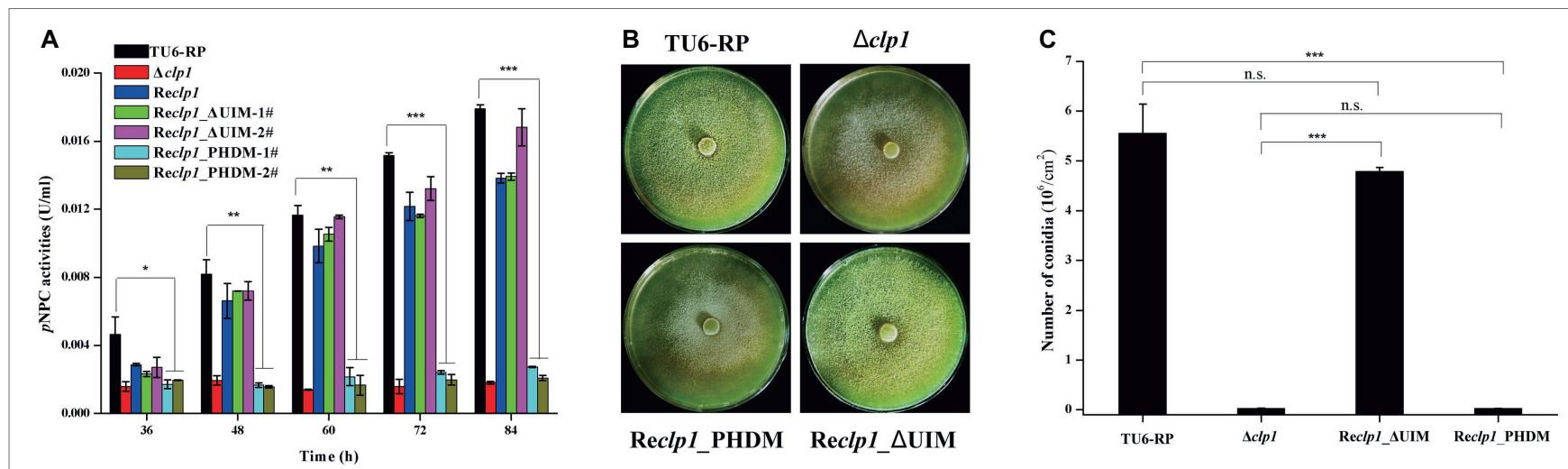

FIGURE 4 | The integrity of the PHD is required for cellulase expression and conidiation. (A) Extracellular pNPC hydrolytic activities of the culture supernatant from the control strain TU6-RP, and the recombinant strains $\triangle$ clp1, Reclp1, Reclp1_PHDM, and Reclp1_ $\Delta$ UIM cultured on 1\% (w/v) Avicel. (B) Conidia formation of the control strain TU6-RP, and the recombinant strains $\triangle c / p 1$, Reclp1, Reclp1_PHDM, and Reclp1_ $\Delta$ UIM on malt extract agar plates at $30^{\circ} \mathrm{C}$ for 5 days. (C) Counting of conidia produced by the strains in (B). Significant differences ( $t$ test, ${ }^{\star} p<0.05,{ }^{* \star} p<0.01,{ }^{* \star \star} p<0.001$ ) were observed in (hemi)cellulase production and conidiation. Values represent the mean of three biological replicates. Error bars are the SD from these replicates.

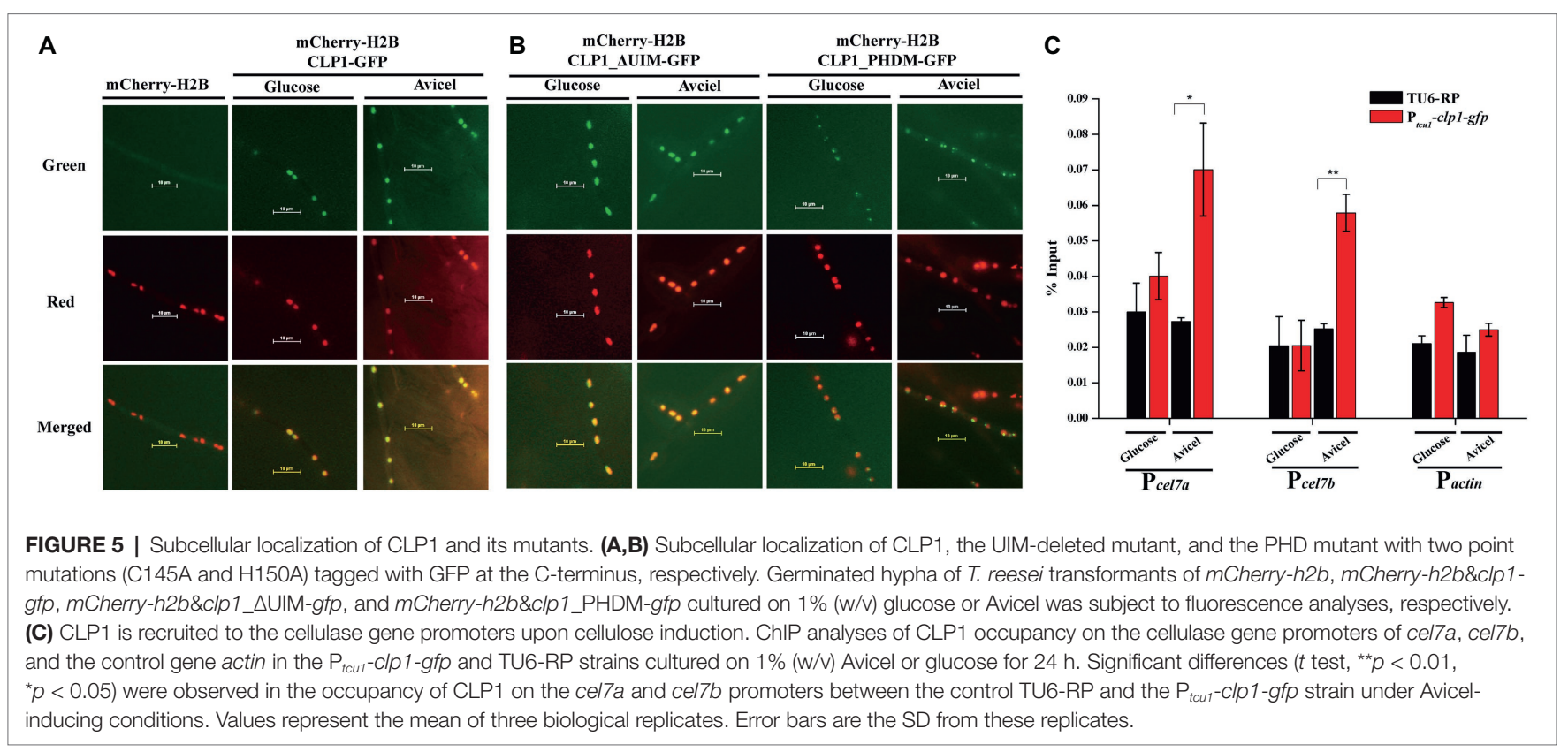

PHD protein involved in activating or repressing a number of genes in $S$. cerevisiae via mediating the recruitment of chromatin modifiers to the target gene promoter regions (Papamichos-Chronakis et al., 2002; Wang et al., 2011). This analysis retrieved the CLP1 protein sharing quite low sequence identity (19\%) and similarity (29\%) with CTI6. Whereas it is still arbitrary to assign CLP1 as a CTI6 homolog in T. reesei due to their low sequence identity, homologs of CLP1 are widely distributed in filamentous fungi including Trichoderma, Fusarium, Neurospora, Penicillium, and Aspergillus species, sharing relatively higher sequence identity (30-98\%) with CLP1, although none of these homologs have been characterized.

We presented evidence that CLP1 is an important positive regulator of the induced cellulase gene expression in T. reesei.
Similar to CTI6 and other transcriptional regulators, CLP1 is targeted to the nucleus although it does not have the obvious nucleus localization sequence (NLS). An explanation for this anomaly may be that CLP1 is targeted to the nucleus with the help of other as-yet-unknown partners with NLS by direct or indirect interactions. Moreover, ChIP analyses demonstrated that CLP1 is recruited to promoters of the main cellulase genes specifically upon cellulose induction, further supporting that CLP1 directly regulates cellulase gene expression. In addition, CLP1 is also found to be functional in conidia formation, which is an independent physiological process from cellulase expression, suggesting that CLP1 simultaneously exerts its regulatory effect on genes involved in sporulation. In $A$. nidulans, activation of $b r l A$ expression is an essential step of conidiation 

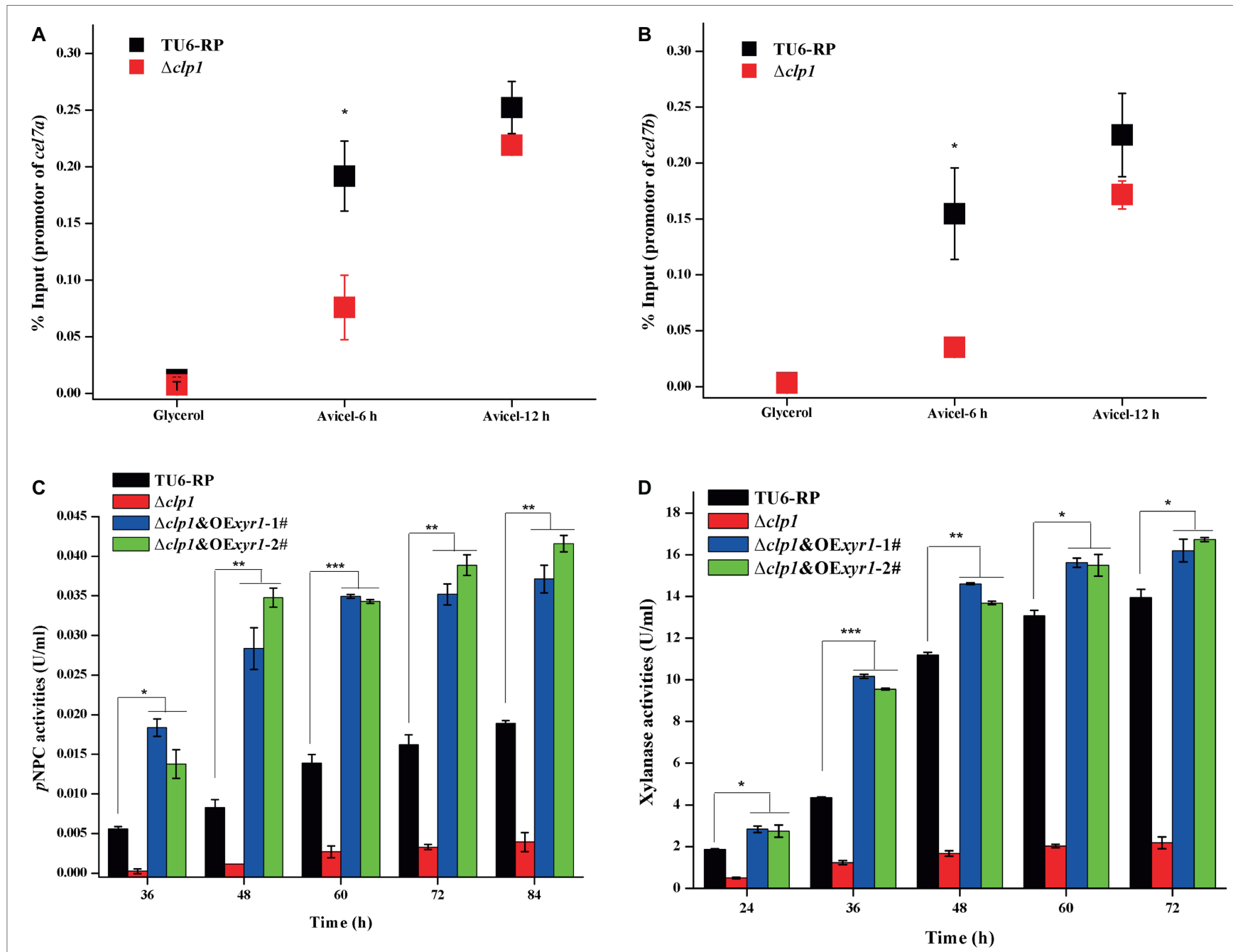

E

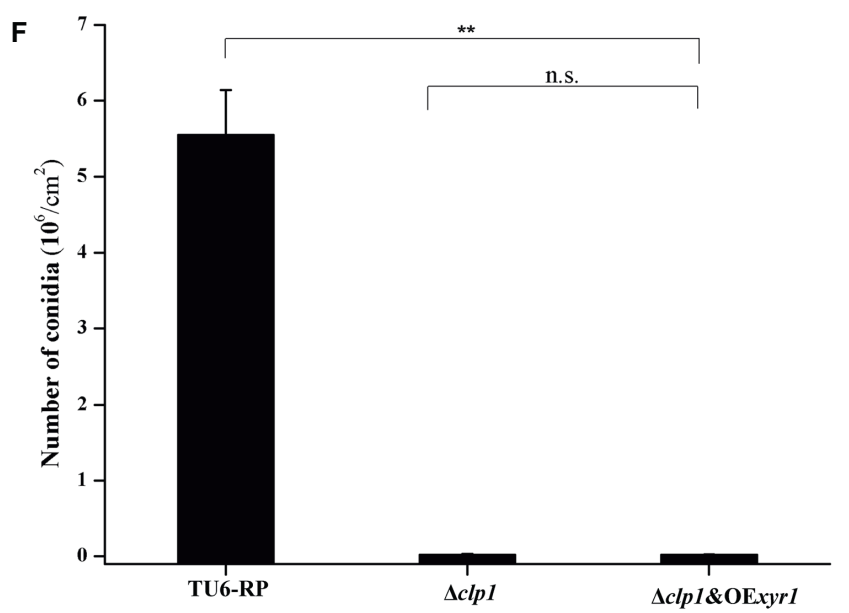

FIGURE 6 | Overexpression of XYR1 fully rescued the defect in cellulase production but not conidiation resulting from clp1 deletion. (A,B) ChIP analyses of XYR1 occupancy on cel7a (A) and cel7b (B) promoters in the $\triangle c / p 1$ and TU6-RP strains after cultivation on 1\% (v/v) glycerol or $1 \%$ (W/v) Avicel for 6 and 12 h. (C,D) Extracellular pNPC hydrolytic activities (C) and xylanase activities (D) of the culture supernatant from TU6-RP, $\Delta c / p 1$, and $\Delta c / p 1 \& O E x y r 1$ strains cultured on 1\% (w/v) Avicel or $0.5 \%(\mathrm{w} / \mathrm{v})$ xylan. (E,F) Conidia formation of the control strain TU6-RP, $\Delta c / p 1$, and $\Delta c / p 1 \& \mathrm{O}$ Exyr1 strains incubated on malt extract agar plates at $30^{\circ} \mathrm{C}$ for 5 days $(\mathbf{E})$ and conidia counting (F). Significant differences ( $t$ test, ${ }^{*} p<0.05,{ }^{\star \star} p<0.01,{ }^{\star \star *} p<0.001$ ) were observed in the (hemi)cellulase production and conidiation between the control strain TU6-RP and the $\triangle$ clp 1 \&OExyr1 strain. Values represent the mean of three biological replicates. Error bars are the SD from these replicates. 
(Adams et al., 1988). Knockout of brlA results in a bristle-like structure that produces an elongated stalk and fails to develop vesicles or any other subsequent structures (Clutterbuck, 1969; Boylan et al., 1987). By contrast, overexpression of brlA leads to the formation of viable conidia directly from the hyphal tips (Adams et al., 1988). Although the homologous protein of BRLA has not been found in T. reesei, several other regulators including LAE1 and VEL1 that participate in modulating sporulation and cellulase production have been identified (Seiboth et al., 2012; Karimi Aghcheh et al., 2014). However, the detailed genetic relationship between CLP1 and these regulators in controlling sporulation warrants further study.

CLP1 contains a conserved PHD finger ( $\sim 60 \mathrm{aa})$, which is also observed in CTI6, although its role in CTI6 function has not been clarified. The PHD finger occurs in a set of proteins, the majority of which are involved in chromatin-mediated transcriptional regulation either directly or through protein-protein interactions (Aasland et al., 1995; Schultz et al., 2001). However, evidence exist that the PHD is dispensable for specific interactions with transcriptional regulatory complexes including GCN5/SAGA but is essential for CTI6 function at the GAL1 promoter (Papamichos-Chronakis et al., 2002). On the other hand, the integrity of CTI6 PHD finger is not required for its targeting to the nucleus (Puig et al., 2004). In accordance with these results, our data showed that the integrity of CLP1 PHD finger is essential for its regulatory activity in cellulase expression and conidia formation, as demonstrated by the observation that the double point mutant in PHD is similarly defective for cellulase synthesis and conidiation. However, in contrast with the normal nuclear localization of CTI6 PHD mutant in S. cerevisiae (Puig et al., 2004), CLP1_PDHM displayed a subtly different pattern of nuclear accumulation compared with WT CLP1. One could speculate that the malfunction of the $\operatorname{clp} 1$ double point mutant resulted from its abnormal nuclear distribution. In contrast with the PHD, removal of the UIM from CLP1, which is present in homologs of most filamentous fungi but not in S. cerevisiae CTI6, did not influence the cellular localization and function of CLP1. The function of UIM in CLP1 as well as its fungal homologs awaits further investigation. Nonetheless, these mutational analyses suggested that $T$. reesei CLP1 may adopt a quite different folded structure from S. cerevisiae CTI6 and thus CLP1 probably represents a novel transcriptional regulator.

XYR1 is the dominating transcriptional activator in T. reesei cellulase gene expression. While the absence of XYR1 abolished almost all the cellulase and hemicellulase gene expression (Stricker et al., 2006; Ma et al., 2016), its overexpression results in a full expression of cellulases even under non-inducing conditions (Lv et al., 2015). Although XYR1 occupancy on cellulase gene promoters as well as its transcriptional expression was compromised in the clp1 null mutant at the early cultivation phase on cellulose $(6 \mathrm{~h})$, it should be noticed that both were comparable to those in the control strain when the cultivation period was extended to $12 \mathrm{~h}$ (Figures 3B,G, 6A). Thus, the defective cellulase gene expression during the whole inducing process cannot be solely accounted for by the decreased XYR1 binding to cellulase gene promoters at the early stage of induction. Possibility exists that CLP1 either contributes to
XYR1-mediated transcriptional activity when recruited to promoters or just acts in parallel with XYR1 in the transcriptional activation process. The observation that XYR1 overexpression fully rescued the defect in cellulase production but not conidiation in clp1 mutant further supports the above note that excessive XYR1 may override the requirement for CLP1. Unlike XYR1, ACE3 overexpression is not able to rescue the defective cellulase production in $\Delta c l p 1$. This observation is supported by the observation that ace 3 expression is not upregulated with XYR1 overexpression, which leads to full cellulase gene expression under non-inducing conditions (data not shown). Considering that CLP1 contains the PHD finger that is commonly observed in proteins that may participate in modifying chromatin as well as mediating molecular interactions in gene transcription (Aasland et al., 1995; Sanchez and Zhou, 2011), we speculate that CLP1 acts as a cofactor to contribute to recruiting unknown factors such as chromatin modifiers or remodelers playing important roles in the process of assembling transcriptional machinery and thus activation of cellulase genes.

\section{DATA AVAILABILITY}

The raw data supporting the conclusions of this manuscript will be made available by the authors, without undue reservation, to any qualified researcher.

\section{ETHICS STATEMENT}

No human studies are presented in this manuscript. No animal studies are presented in this manuscript. No potentially identifiable human images or data is presented in this study.

\section{AUTHOR CONTRIBUTIONS}

LW and RY performed the experiments. YC, FZ, XM, YZ, and GC performed data analysis. WL, WZ, and WL designed the project. WL, WZ, and LW wrote the manuscript.

\section{FUNDING}

This work is supported by grants from the National Natural Science Foundation of China (31770047, 31800024, and 31670040), Shandong Technology Innovation Center of Synthetic Biology (sdsynbio-2018PY-01), and State Key Laboratory of Microbial Technology Open Projects Fund (Project NO. M2017-10).

\section{SUPPLEMENTARY MATERIAL}

The Supplementary Material for this article can be found online at: https://www.frontiersin.org/articles/10.3389/fmicb.2019.01700/ full\#supplementary-material 


\section{REFERENCES}

Aasland, R., Gibson, T. J., and Stewart, A. F. (1995). The PHD finger: implications for chromatin-mediated transcriptional regulation. Trends Biochem. Sci. 20, 56-59. doi: 10.1016/S0968-0004(00)88957-4

Adams, T. H., Boylan, M. T., and Timberlake, W. E. (1988). BrlA is necessary and sufficient to direct conidiophore development in Aspergillus nidulans. Cell 54, 353-362. doi: 10.1016/0092-8674(88)90198-5

Antoniêto, A. C., De Paula, R. G., Castro Ldos, S., Silva-Rocha, R., Persinoti, G. F., and Silva, R. N. (2016). Trichoderma reesei CRE1-mediated carbon catabolite repression in response to sophorose through RNA sequencing analysis. Curr. Genomics 17, 119-131. doi: 10.2174/1389202917666151116212901

Aro, N., Saloheimo, A., Ilmen, M., and Penttilä, M. (2001). ACEII, a novel transcriptional activator involved in regulation of cellulase and xylanase genes of Trichoderma reesei. J. Biol. Chem. 276, 24309-24314. doi: 10.1074/jbc.M003624200

Bhushan, B., Erdmann, A., Zhang, Y., Belle, R., Johannson, C., Oppermann, U., et al. (2018). Investigations on small molecule inhibitors targeting the histone H3K4 tri-methyllysine binding PHD-finger of JmjC histone demethylases. Bioorg. Med. Chem. 26, 2984-2991. doi: 10.1016/j.bmc.2018.03.030

Bienz, M. (2006). The PHD finger, a nuclear protein-interaction domain. Trends Biochem. Sci. 31, 35-40. doi: 10.1016/j.tibs.2005.11.001

Boylan, M. T., Mirabito, P. M., Willett, C. E., Zimmerman, C. R., and Timberlake, W. E. (1987). Isolation and physical characterization of three essential conidiation genes from Aspergillus nidulans. Mol. Cell. Biol. 7, 3113-3118. doi: $10.1128 / \mathrm{mcb} .7 .9 .3113$

Buchberger, A. (2002). From UBA to UBX: new words in the ubiquitin vocabulary. Trends Cell Biol. 12, 216-221. doi: 10.1016/S0962-8924(02)02269-9

Cao, Y., Zheng, F., Wang, L., Zhao, G., Chen, G., Zhang, W., et al. (2017). Rce1, a novel transcriptional repressor, regulates cellulase gene expression by antagonizing the transactivator Xyr1 in Trichoderma reesei. Mol. Microbiol. 105, 65-83. doi: $10.1111 / \mathrm{mmi} .13685$

Chen, L., Zou, G., Wang, J., Wang, J., Liu, R., Jiang, Y., et al. (2016). Characterization of the $\mathrm{Ca}(2+)$-responsive signaling pathway in regulating the expression and secretion of cellulases in Trichoderma reesei Rut-C30. Mol. Microbiol. 100, 560-575. doi: $10.1111 / \mathrm{mmi} .13334$

Church, M. C., and Fleming, A. B. (2018). A role for histone acetylation in regulating transcription elongation. Transcription 9, 225-232. doi: $10.1080 / 21541264.2017 .1394423$

Clutterbuck, A. J. (1969). A mutational analysis of conidial development in Aspergillus nidulans. Genetics 63, 317-327.

Crawford, R. A., and Pavitt, G. D. (2019). Translational regulation in response to stress in Saccharomyces cerevisiae. Yeast 36, 5-21. doi: 10.1002/yea.3349

Dos Santos Castro, L., De Paula, R. G., Antoniêto, A. C., Persinoti, G. F., Silva-Rocha, R., and Silva, R. N. (2016). Understanding the role of the master regulator XYR1 in Trichoderma reesei by global transcriptional analysis. Front. Microbiol. 7:175. doi: 10.3389/fmicb.2016.00175

Druzhinina, I. S., and Kubicek, C. P. (2017). Genetic engineering of Trichoderma reesei cellulases and their production. Microb. Biotechnol. 10, 1485-1499. doi: 10.1111/1751-7915.12726

Häkkinen, M., Valkonen, M. J., Westerholm-Parvinen, A., Aro, N., Arvas, M., Vitikainen, M., et al. (2014). Screening of candidate regulators for cellulase and hemicellulase production in Trichoderma reesei and identification of a factor essential for cellulase production. Biotechnol. Biofuels 7:14. doi: 10.1186/1754-6834-7-14

Hall, B. G. (2013). Building phylogenetic trees from molecular data with MEGA. Mol. Biol. Evol. 30, 1229-1235. doi: 10.1093/molbev/mst012

Han, B. K., and Emr, S. D. (2011). Phosphoinositide [PI $\left.(3,5) \mathrm{P}_{2}\right]$ lipid-dependent regulation of the general transcriptional regulator Tup1. Genes Dev. 25, 984-995. doi: 10.1101/gad.1998611

Han, B. K., and Emr, S. D. (2013). The phosphatidylinositol 3,5-bisphosphate (PI $(3,5) \mathrm{P}_{2}$ )-dependent Tup1 conversion (PIPTC) regulates metabolic reprogramming from glycolysis to gluconeogenesis. J. Biol. Chem. 288, 20633-20645. doi: 10.1074/jbc.M113.452813

Heckman, K. L., and Pease, L. R. (2007). Gene splicing and mutagenesis by PCR-driven overlap extension. Nat. Protoc. 2, 924-932. doi: 10.1038/nprot.2007.132

Hofmann, K., and Falquet, L. (2001). A ubiquitin-interacting motif conserved in components of the proteasomal and lysosomal protein degradation systems. Trends Biochem. Sci. 26, 347-350. doi: 10.1016/s0968-0004(01)01835-7
Karimi Aghcheh, R., Nemeth, Z., Atanasova, L., Fekete, E., Paholcsek, M., Sandor, E., et al. (2014). The VELVET A orthologue VEL1 of Trichoderma reesei regulates fungal development and is essential for cellulase gene expression. PLoS One 9:e112799. doi: 10.1371/journal.pone.0112799

Laemmli, U. K. (1970). Cleavage of structural proteins during the assembly of the head of bacteriophage T4. Nature 227, 680-685. doi: 10.1038/227680a0

Lv, X., Zheng, F., Li, C., Zhang, W., Chen, G., and Liu, W. (2015). Characterization of a copper responsive promoter and its mediated overexpression of the xylanase regulator 1 results in an induction-independent production of cellulases in Trichoderma reesei. Biotechnol. Biofuels 8:67. doi: 10.1186/s13068-015-0249-4

Ma, L., Chen, L., Zhang, L., Zou, G., Liu, R., Jiang, Y., et al. (2016). RNA sequencing reveals Xyr1 as a transcription factor regulating gene expression beyond carbohydrate metabolism. Biomed. Res. Int. 2016:4841756. doi: $10.1155 / 2016 / 4841756$

Mach, R. L., Schindler, M., and Kubicek, C. P. (1994). Transformation of Trichoderma Reesei based on hygromycin B resistance using homologous expression signals. Curr. Genet. 25, 567-570. doi: 10.1007/BF00351679

Mello-de-Sousa, T. M., Rassinger, A., Pucher, M. E., Dos Santos Castro, L., Persinoti, G. F., Silva-Rocha, R., et al. (2015). The impact of chromatin remodelling on cellulase expression in Trichoderma reesei. BMC Genomics 16:588. doi: 10.1186/s12864-015-1807-7

Mizzen, C. A., and Allis, C. D. (1998). Linking histone acetylation to transcriptional regulation. Cell. Mol. Life Sci. 54, 6-20.

Oldham, C. E., Mohney, R. P., Miller, S. L., Hanes, R. N., and O'bryan, J. P. (2002). The ubiquitin-interacting motifs target the endocytic adaptor protein epsin for ubiquitination. Curr. Biol. 12, 1112-1116. doi: 10.1016/ S0960-9822(02)00900-4

Papamichos-Chronakis, M., Petrakis, T., Ktistaki, E., Topalidou, I., and Tzamarias, D. (2002). Cti6, a PHD domain protein, bridges the Cyc8-Tup1 corepressor and the SAGA coactivator to overcome repression at GAL1. Mol. Cell 9, 1297-1305. doi: 10.1016/S1097-2765(02)00545-2

Penttilä, M., Nevalainen, H., Rättö, M., Salminen, E., and Knowles, J. (1987). A versatile transformation system for the cellulolytic filamentous fungus Trichoderma reesei. Gene 61, 155-164. doi: 10.1016/0378-1119(87)90110-7

Polo, S., Sigismund, S., Faretta, M., Guidi, M., Capua, M. R., Bossi, G., et al. (2002). A single motif responsible for ubiquitin recognition and monoubiquitination in endocytic proteins. Nature 416, 451-455. doi: $10.1038 / 416451 \mathrm{a}$

Puig, S., Lau, M., and Thiele, D. J. (2004). Cti6 is an Rpd3-Sin3 histone deacetylase-associated protein required for growth under iron-limiting conditions in Saccharomyces cerevisiae. J. Biol. Chem. 279, 30298-30306. doi: $10.1074 /$ jbc.M313463200

Saloheimo, A., Aro, N., Ilmen, M., and Penttila, M. (2000). Isolation of the acel gene encoding a Cys(2)-His(2) transcription factor involved in regulation of activity of the cellulase promoter $c b h 1$ of Trichoderma reesei. J. Biol. Chem. 275, 5817-5825. doi: 10.1074/jbc.275.8.5817

Sanchez, R., and Zhou, M. M. (2011). The PHD finger: a versatile epigenome reader. Trends Biochem. Sci. 36, 364-372. doi: 10.1016/j.tibs.2011.03.005

Schmittgen, T. D., and Livak, K. J. (2008). Analyzing real-time PCR data by the comparative C(T) method. Nat. Protoc. 3, 1101-1108. doi: 10.1038/nprot.2008.73

Schmoll, M. (2018). Regulation of plant cell wall degradation by light in Trichoderma. Fungal Biol. Biotechnol. 5:10. doi: 10.1186/s40694-018-0052-7

Schultz, D. C., Friedman, J. R., and Rauscher, F. J. III (2001). Targeting histone deacetylase complexes via KRAB-zinc finger proteins: the PHD and bromodomains of KAP-1 form a cooperative unit that recruits a novel isoform of the Mi-2alpha subunit of NuRD. Genes Dev. 15, 428-443. doi: 10.1101/gad.869501

Seiboth, B., Karimi, R. A., Phatale, P. A., Linke, R., Hartl, L., Sauer, D. G., et al. (2012). The putative protein methyltransferase LAE1 controls cellulase gene expression in Trichoderma reesei. Mol. Microbiol. 84, 1150-1164. doi: 10.1111/j.1365-2958.2012.08083.x

Strauss, J., Mach, R. L., Zeilinger, S., Hartler, G., Stoffler, G., Wolschek, M., et al. (1995). Cre1, the carbon catabolite repressor protein from Trichoderma reesei. FEBS Lett. 376, 103-107. doi: 10.1016/0014-5793(95)01255-5

Stricker, A. R., Grosstessner-Hain, K., Wurleitner, E., and Mach, R. L. (2006). Xyrl (xylanase regulator 1) regulates both the hydrolytic enzyme system and D-xylose metabolism in Hypocrea jecorina. Eukaryot. Cell 5, 2128-2137. doi: 10.1128/EC.00211-06 
Takashima, S., Iikura, H., Nakamura, A., Masaki, H., and Uozumi, T. (1996). Analysis of Cre1 binding sites in the Trichoderma reesei cbh1 upstream region. FEMS Microbiol. Lett. 145, 361-366. doi: 10.1111/j.1574-6968.1996. tb08601.x

Tamura, K., Stecher, G., Peterson, D., Filipski, A., and Kumar, S. (2013). MEGA6: molecular evolutionary genetics analysis version 6.0. Mol. Biol. Evol. 30, 2725-2729. doi: 10.1093/molbev/mst197

Tani, S., Kawaguchi, T., and Kobayashi, T. (2014). Complex regulation of hydrolytic enzyme genes for cellulosic biomass degradation in filamentous fungi. Appl. Microbiol. Biotechnol. 98, 4829-4837. doi: 10.1007/ s00253-014-5707-6

Vidal, M., and Gaber, R. F. (1991). RPD3 encodes a second factor required to achieve maximum positive and negative transcriptional states in Saccharomyces cerevisiae. Mol. Cell. Biol. 11, 6317-6327. doi: 10.1128/ MCB.11.12.6317

Wang, L., Lv, X., Cao, Y., Zheng, F., Meng, X., Shen, Y., et al. (2019). A novel transcriptional regulator RXE1 modulates the essential transactivator XYR1 and cellulase gene expression in Trichoderma reesei. Appl. Microbiol. Biotechnol. 103, 4511-4523. doi: 10.1007/s00253-019-09739-6

Wang, L., Zheng, F., Zhang, W., Zhong, Y., Chen, G., Meng, X., et al. (2018). A copper-controlled RNA interference system for reversible silencing of target genes in Trichoderma reesei. Biotechnol. Biofuels 11:33. doi: 10.1186/ s13068-018-1038-7

Wang, S. S., Zhou, B. O., and Zhou, J. Q. (2011). Histone H3 lysine 4 hypermethylation prevents aberrant nucleosome remodeling at the $\mathrm{PHO5}$ promoter. Mol. Cell. Biol. 31, 3171-3181. doi: 10.1128/MCB.05017-11

Xin, Q., Gong, Y., Lv, X., Chen, G., and Liu, W. (2013). Trichoderma reesei histone acetyltransferase Gcn5 regulates fungal growth, conidiation, and cellulase gene expression. Curr. Microbiol. 67, 580-589. doi: 10.1007/ s00284-013-0396-4
Zhang, W., Cao, Y., Gong, J., Bao, X., Chen, G., and Liu, W. (2015). Identification of residues important for substrate uptake in a glucose transporter from the filamentous fungus Trichoderma reesei. Sci. Rep. 5:13829. doi: 10.1038/srep13829

Zhang, W., Kou, Y., Xu, J., Cao, Y., Zhao, G., Shao, J., et al. (2013). Two major facilitator superfamily sugar transporters from Trichoderma reesei and their roles in induction of cellulase biosynthesis. J. Biol. Chem. 288, 32861-32872. doi: $10.1074 /$ jbc.M113.505826

Zheng, F., Cao, Y., Wang, L., Lv, X., Meng, X., Zhang, W., et al. (2017). The mating type locus protein MAT1-2-1 of Trichoderma reesei interacts with Xyr1 and regulates cellulase gene expression in response to light. Sci. Rep. 7:17346. doi: 10.1038/s41598-017-17439-2

Zhou, Q., Xu, J., Kou, Y., Lv, X., Zhang, X., Zhao, G., et al. (2012). Differential involvement of beta-glucosidases from Hypocrea jecorina in rapid induction of cellulase genes by cellulose and cellobiose. Eukaryot. Cell 11, 1371-1381. doi: 10.1128/EC.00170-12

Znameroski, E. A., and Glass, N. L. (2013). Using a model filamentous fungus to unravel mechanisms of lignocellulose deconstruction. Biotechnol. Biofuels 6:6. doi: 10.1186/1754-6834-6-6

Conflict of Interest Statement: The authors declare that the research was conducted in the absence of any commercial or financial relationships that could be construed as a potential conflict of interest.

Copyright (c) 2019 Wang, Yang, Cao, Zheng, Meng, Zhong, Chen, Zhang and Liu. This is an open-access article distributed under the terms of the Creative Commons Attribution License (CC BY). The use, distribution or reproduction in other forums is permitted, provided the original author(s) and the copyright owner(s) are credited and that the original publication in this journal is cited, in accordance with accepted academic practice. No use, distribution or reproduction is permitted which does not comply with these terms. 